\title{
A multiphysics approach to modelling the erosion-enhanced corrosion of low-alloy carbon steel in chloride containing environments
}

\author{
Magdalena Walczak ${ }^{\mathrm{a}^{*}}$, Shayan Sharifi ${ }^{\mathrm{b}}$, Margaret M Stack ${ }^{\mathrm{c}}$
}

\begin{abstract}
a) Department of Mechanical and Metallurgical Engineering, School of Engineering, Pontificia Universidad Católica de Chile, Vicuña Mackenna 4860, Macul, Santiago, Chile

b) Faculty of Engineering, Dyson School of Design Engineering, Imperial College London, South Kensington Campus, London SW7 2AZ, UK

c) Department of Mechanical Engineering, University of Strathclyde, 75 Montrose Street, G1 1XJ Glasgow, UK

*corresponding author, Email: mwalczak@ing.puc.cl
\end{abstract}

\begin{abstract}
To be written at the end

The effects of erosion-enhanced corrosion of low-alloys carbon steel have been studied experimentally by measuring polarization curves in an impinging jet configuration and a multiphysics algorithm has been develop to describe the erosion-corrosion interactions. The aims of the research are to improve the longevity of transporation processes for Copper mining in Chiles. In this study an electrode of API 5L X65 steel was exposed to electrolyte jet of different chloride content $(0.005,0.05$ or $0.5 \mathrm{M} \mathrm{NaCa})$ containing silica particles $(250-350 \mu \mathrm{m})$. The simulated polarization curves were obtained by adopting a coupled electrochemical-transportreaction model. The effect of erosion on the reactions was found to be well described as a proportionality factor of the electrochemical reaction' kinetics determined for the cases with, and without, the erodent. It is thought that the presence of chloride contributes mostly through increased conductivity of the electrolyte.
\end{abstract}

\section{KEYWORDS}
A: Carbon-steel, Slurry
B: Impinging jet, Erosion-corrosion, Numerical simulation, Synergy 
C: Kinetic parameters

Appendix of terms

Suggest include Appendix of all mathematical terms 


\section{Highlights}

- A numerical simulation is conducted of of the impinging jet experiment in erosion-corrosion

- The erosion-enhanced corrosion is described as acceleration of reaction under impingement

- It is found that the effect of particle impingement is more significant for the the anodic reaction

- The influence of chloride concentration results mainly in an increase in the conductivity of the electrolyte 


\section{Introduction}

The wastage of metallic alloys by a flowing mineral slurry involves a combination of abrasion, erosion, and corrosion. Despite the engineering definitions of abrasion and erosion [1], the two terms are sometimes used interchangeably in reference to pipeline flow and slurry, but the totality of the mechanism is most frequently termed erosion-corrosion, encompassing the sum of mass losses attributed to corrosion alone, erosion alone, and the synergy caused by interaction between the two. Low-alloy carbon steel, as it is often the material of choice for construction of long range slurry pipelines in for example Copper mining, is inevitably subject to erosioncorrosion and this is the motivation on the mechanistice studies below.

Whereas corrosion and erosion are relatively well understood as separate processes, the synergy term is a multifactorial problem [2-6] that requires taking into account: 1) properties of the alloy target [7-15]: its hardness, modulus of elasticity, toughness, chemical composition and microstructure, 2) characteristics of the dispersed phase [16-26]: its density, hardness, size, angularity and concentration of the slurry particle are the most relevant, as well as 3) properties and conditions of the flow medium in which the particles are suspended [27-37]: its velocity, impact angle, viscosity, $\mathrm{pH}$, pressure and chemical composition.

The erosion-corrosion synergy [38] is customarily separated into erosion-enhanced corrosion and corrosion-enhanced erosion, e.g. [39-43]. In case of passive alloys, a critical flow velocity is often defined as marking the transition from a passivation-dominant to erosion-dominant mechanism of degradation $[33,44]$. Determining the fraction of total weight loss attributed to corrosion, both straightforward and erosion-enhanced, is crucial for the design of a possible mitigation strategy. In a corrosion dominated system, addition of a corrosion inhibitor might be effective [45-47], whereas no such effect should be expected in erosion dominated systems operated under critical flow velocity [48].

The research phase on identifying the mechanisms of E-C synergy is an on-going challenge [49], because of the high number of individual processes. These processes can be summarized by a semi-empirical model [50-52] that would relate the previously cited parameters with one or more of the following mechanisms: damage of the passive film by the erodent $[53,54]$, strain hardening of the target [55-58], surface deformation due to erosion-induced pitting [59], the effect of erosion increasing the mass transfer coefficient hence erosion-corrosion rate erosion 
[60,61], enhancement of wear due to micro-galvanic corrosion between metallic phases [10] or local anodic/cathodic sites [58], influence of corrosion on the mechanical properties of the target material $[36,62]$, the enhancement of wear by oxide layer formation $[63,64]$, enhancement of wear due to intergranular corrosion $[65,66]$, weakening of eroded metallic flakes/lips on the metal surface due to localized corrosion [57]. However, quantification of all these individual mechanisms for a given alloy/slurry system presents some challenges in practice, and hence, a method for predicting erosion-corrosion performance of an alloy employed in a slurry pipeline based on laboratory data remains to be solved [67]. This paper focuses on the special case of flow-accelerated corrosion [68] that produces erosion-enhanced corrosion in low-alloyed carbon steel, API 5L X65, erosion-corrosion of which has been extensively studied due to its common use as a construction material $[3,11,34,35,69-71]$. Hence, we concentrate mainly here on the effect on erosion on the corrosion rate and use electrochemical data on current to estimate mass change. For simplicity, we thus assume that the effect of corrosion on the erosion rate is negligible in our model.

The amount of weight loss attributed to corrosion, both straightforward and erosion-enhanced, is determined using impinging slurry jet and employing numerical modeling to simulate the flow conditions along with the electrochemical reactions. The approach of linking experimental laboratory data with computational fluid dynamics (CFD) modeling relies on constructing a socalled wear map in function of parameters that are most position sensitive, e.g. local velocity and impact angle, and using the map for predicting erosion-corrosion of a complex geometry for which the local parameters are determined by CFD [72-75]. Whereas modeling the two-phase flow is a challenge on its own due to high turbulence and particle-particle interactions, especially at the high concentrations unavoidable in a slurry [75-80], implementation of the contribution of corrosion poses an independent problem. One solution is to determine corrosion rate based on the rate of mass transfer of corrosion species resulting from the CFD simulation, e.g. [81-83], another is to introduce inflow and consumption of the relevant species determined from an electrochemical measurement, e.g. [84].

In this paper, we study the polarization diagrams measured on carbon steel in exposure to erosion-corrosion produced by an impinging slurry jet. The steady-state distribution of all the involved species and electric potential is determined by the method of finite elements allowing for numerical simulation of the polarization diagrams. This approach, known as coupled 
electrochemical-transport-reaction model (CETR) $[85,86]$ or multi-ion transport and reaction model (MITReM) [87,88], allows coupling partial differential equations describing diffusion, convection, electromigration and homogeneous reactions with boundary conditions given by the heterogeneous reactions of reduction and oxidation [89]. The specific hypothesis being tested is that the effect of erosion on corrosion can be described by a proportionality factor over the kinetics of the electrochemical reactions and that this description holds valid at different concentrations of $\mathrm{NaCl}$, and thus, different conductivities of the flowing medium.

\section{Materials and Method}

The slurry impingement tester used in this study is depicted schematically in Figure 1. The rig was built and calibrated according to Ref [90] to project a jet of $3 \mathrm{~m} / \mathrm{s}$ onto the surface of test specimen at normal angle (upper detail of Figure 1). The test coupons were cut from a decommissioned slurry pipeline made of API 5L X65 steel, of chemical composition as determined by GDOES bulk analysis (Spectruma GDA 750 HR): C 0.06\%, Si 0.21\%, Mn 1.53\%, P $0.01 \%$, S $0.001 \%$, V $0.03 \%$ and Fe balance. Test surface of the specimen was covered with a duct tape, exposing a circular surface area of $1 \mathrm{~cm}$ diameter, aligned with the center of the jet impact. The erodent was silica particles crushed and sieved to contain articles sizes between 250 and $350 \mu \mathrm{m}$. Concentration of the silica particles was kept constant for all experiments by setting the position of suction valve and rotation frequency of the stirrer to produce a slurry jet of about $5 \% \mathrm{vol}$ of the silica particles.

Electrochemical measurements were completed by a three electrode set-up, using the test specimen, saturated calomel electrode (SCE) and Pt-mesh as the working, reference and auxiliary electrodes, respectively; all connected to an ACM Gill AC potentiostat. Prior each experiment OCP was recorded until stabilization of $1 \mathrm{mV}$ (about $5 \mathrm{~min}$ ) and the polarization curves were measured by polarizing in the anodic direction starting from -0.8 to $+0.9 \mathrm{~V}$ vs OCP at the scan rate of $2.5 \mathrm{mV} / \mathrm{s}$. After completing the measurements, test specimen was removed from the rig, cleaned by acetone and weighed with precision of $0,1 \mathrm{mg}$. The experimental value of corrosion current was estimated by Tafel extrapolation of both anodic and cathodic branched to the value of corrosion potential. 


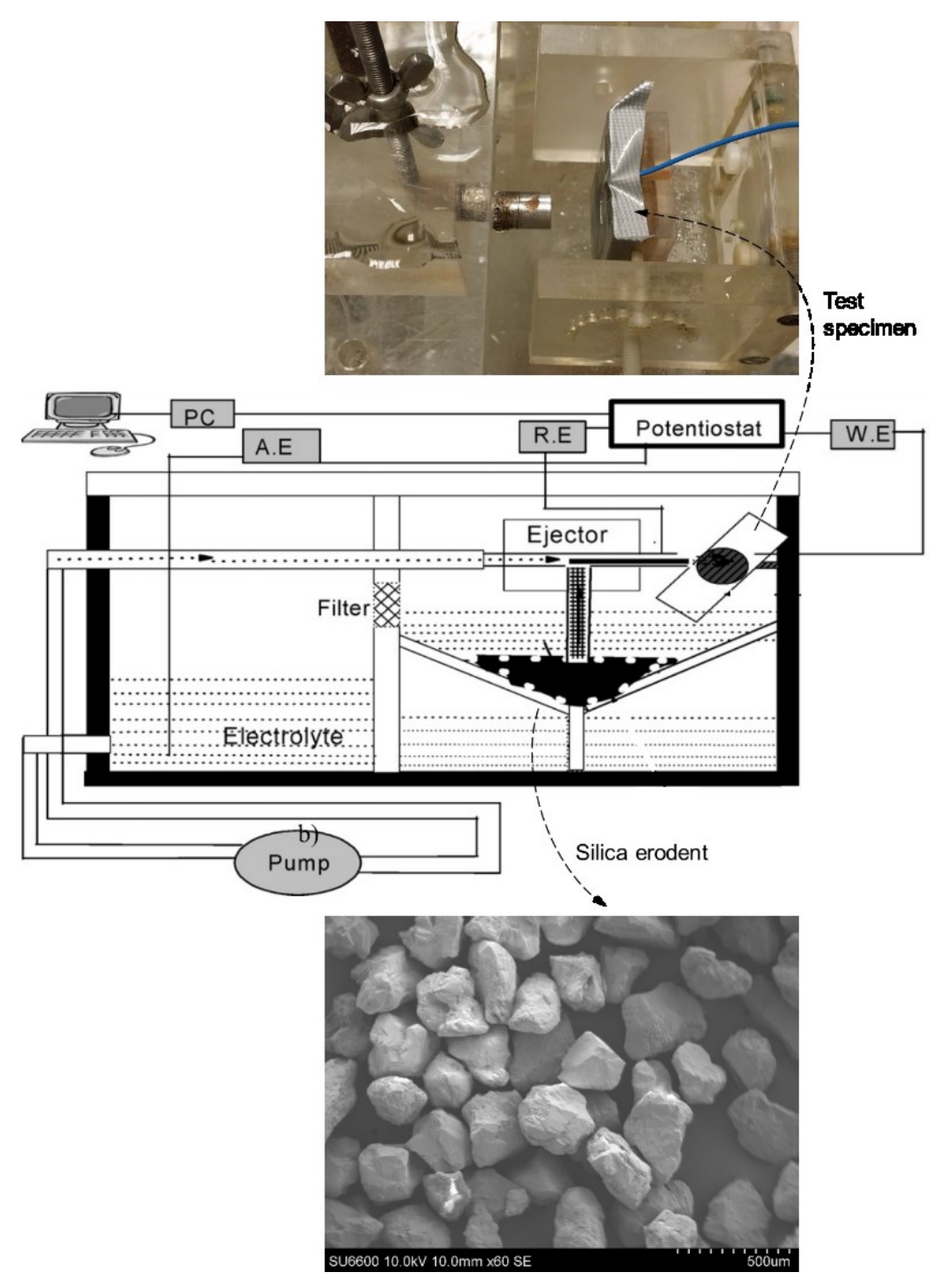

Figure 1. Schematic presentation of the experimental set-up. The diagram of erosion-corrosion test rig has been adapted from Ref. [91]. The upper detail shows the exit nozzle set to project the jet onto the test surface (here the slurry is not running). The bottom detail of silica erodent corresponds with a SEM micrograph. Need scale marker for apparatus

\section{Theory and Calculation}

The model employed in this study is based on multiphysics approach of the finite element method (FEM), combining description of the processes of fluid flow with those of heterogeneous electrochemical and homogeneous chemical reactions. General geometry of the modeled domain is shown in Figure 2a. It represents the jet of electrolyte between outlet of the nozzle (bottom 
boundary) and the metal electrode (top boundary). Due to axial symmetry of the jet, the problem is reduced to two dimensions and only half the jet's cross-section is considered as computational domain.

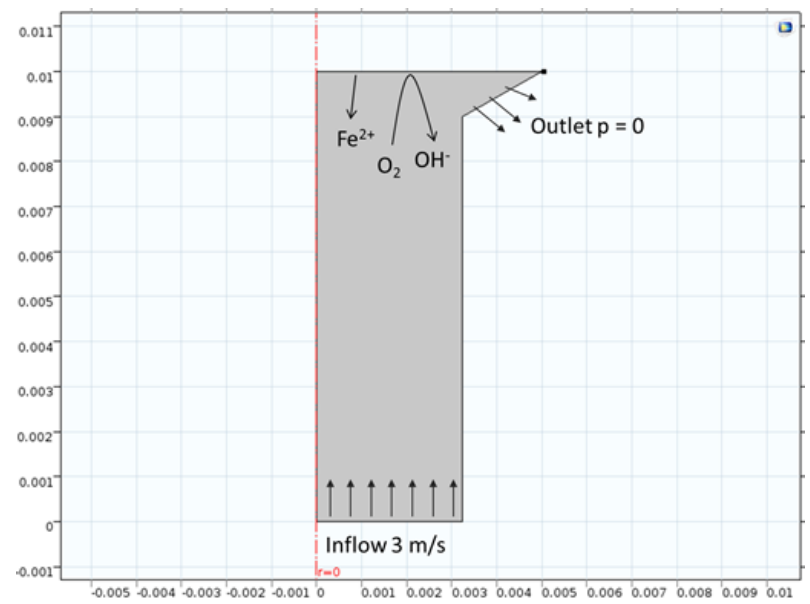

Figure 2. Definition of the axisymmetric model and the boundary conditions of flow. The anodic and cathodic reaactions are indicated at the electrode.

Governing equations. - In order to determine the value of corrosion current, Nernst-Planck equation (Eq. 1) is employed for each of the species involved in chemical or electrochemical reactions:

$$
\frac{\partial c_{n}}{\partial t}=\nabla \cdot\left(-D_{n} \nabla c_{n}-\mathrm{z}_{n} \mu_{n} \mathrm{~F} c_{n} \nabla V\right)+\mathbf{u} \cdot \nabla c_{n}+\mathrm{R}_{n}
$$

where $c_{n}, D_{n}, z_{n}, \mu_{n}$, and $R_{n}$ are the concentration, diffusion coefficient, charge number, electromobility and homogeneous reaction constant of species $n$, respectively. Further, $t, V, \mathrm{~F}$ and $\mathbf{u}$ are time, Faraday constant, electric potential, and velocity field, respectively. In order to implement the flow condition of the jet, the velocity field used in Eq. 1 is determined by the equation of Navier-Stokes:

$$
\rho(\mathbf{u} \nabla) \mathbf{u}=\nabla\left[-p \mathbf{I}+\mu\left(\nabla \mathbf{u}+(\nabla \mathbf{u})^{\mathrm{T}}\right)\right]+\mathbf{F}
$$


where $\rho$ and $\mu$ are the density and dynamic viscosity of the electrolyte, respectively; $\mathbf{I}$ - identity matrix, and $\mathbf{F}$ - volume force vector.

In order to solve all the variables of Eq. 1, the condition of electroneutrality (Eq. 3) is imposed in addition:

$$
\sum_{n} \mathrm{z}_{n} c_{n}=0
$$

Although this condition is rigorously valid only for diluted species [92], which is not entirely true in real systems, its use in this model is justified by the existence of steady state solution [93]. Also, concentrations of all the considered species remain under the upper limit of $10^{-3} \mathrm{~mol} / \mathrm{l}$ and no negative concentrations have been obtained in the calculated results.

Boundary conditions. - At the steel boundary, oxidation of the metal takes place. The steel is considered low alloy; thus the effect of alloying elements is neglected and the displacement reaction of iron is considered irreversible:

$$
\mathrm{Fe} \rightarrow \mathrm{Fe}^{2+}+2 \mathrm{e}^{-}
$$

At the same electrode surface, oxygen reduction reaction (ORR) takes place:

$$
\mathrm{O}_{2}+2 \mathrm{H}_{2} \mathrm{O}+2 \mathrm{e}^{-} \rightarrow 4 \mathrm{OH}^{-}
$$

This reaction is assumed to be the predominant irreversible reduction due to initial neutrality of the electrolyte. The kinetics of ORR has many mechanistic alternatives, depending on the actual $\mathrm{pH}$, and the number and type of individual steps taken into account. In this paper, no $\mathrm{pH}$ dependence is considered because there is no kinetic data available that would allow accurate modeling of Eq. 5, and also, the approximation has been successfully used by other authors [85]. The electrochemical reactions given by Eqs. 4-5 are implemented into the model by means of the Butler-Volmer expressions imposed on the electrode's surface:

$$
j_{n}=z_{n} \mathrm{~F} k_{n} c_{n} \exp \left(\frac{z_{n}}{\left|z_{n}\right|} \frac{V-E_{n}^{\mathrm{o}}}{a_{n}}\right)
$$

where $k_{n}$ is the kinetic constant of species $n, E_{n}^{0}$ and $a_{n}$ are the standard reduction potential and Tafel coefficient, respectively. The values of Tafel coefficients and kinetics constants were fit 
parameters obtained by a procedure similar to that described by Thebault et al. [94] with the additional restriction of providing good fit of all the data with the same set of Tafel constants. The last assumption is motivated by the relatively high flow velocity as compared with the effect of chlorine on the reaction kinetics of the anodic and cathodic reactions (Eq. 4 and 5). It should be noted that the variable $V$ in Eqs. 1 and 6 (electric potential) corresponds with potential difference between the surface of metal $\left(V_{\mathrm{m}}\right)$ and the electrolyte $\left(V_{\text {sol }}\right)$ :

$$
V=V_{\mathrm{m}}-V_{\mathrm{sol}}
$$

The molecular fluxes $N$ of the species $\mathrm{Fe}^{2+}, \mathrm{O}_{2}$ and $\mathrm{OH}^{-}$resulting from Eqs. 4-5 are determined by Eq. 8 :

$$
-\mathbf{n} N_{n}=-\frac{\left|z_{n}\right|}{z_{n}^{2}} j_{n}
$$

where $\mathbf{n}$ is a vector normal to the electrode's surface.

Boundary conditions for the problem of flow (Eq. 2) include a constant inflow velocity $v_{\text {in }}$ at the outlet of the nozzle and no flow condition at the surface of the electrode. The outer boundary of the flowing jet is considered to move with $v=v_{\text {in }}$ in the direction of the jet, whereas the outflow boundary is conditioned by atmospheric pressure of $1 \mathrm{~atm}$.

Finally, the effect of erosion on the current is implemented as modification Eq. 6:

$$
j_{n, \mathrm{E}-\mathrm{C}}=k_{\mathrm{E}-\mathrm{C}} j_{n}
$$

where $k_{\mathrm{E}-\mathrm{C}}$ is a constant describing the enhancement of either anodic or cathodic current density attributed to erosion. The quantity of current is determined as the integral value of the current distribution over the working electrode. The value of $k_{\mathrm{E}-\mathrm{C}}$ is determined from the corrosion current, i.e., the value of anodic current at steady-state in which its quantity is equal to the cathodic current. More details on the method and its precision can be found in Ref. [95].

Chemical reactions in the domain. - In the bulk of the electrolyte dissociation of water is taken into account with both forward and backward kinetics: 


$$
\mathrm{H}^{+}+\mathrm{OH}^{-} \underset{k_{\mathrm{b}, \mathrm{H}_{2} \mathrm{O}}}{\stackrel{k_{\mathrm{f}, \mathrm{H}_{2} \mathrm{O}}}{\rightleftarrows}} \mathrm{H}_{2} \mathrm{O}
$$

Mesh and calculation.- The entire model has been implemented in COMSOL 5.1. The values of the parameters are summarized in Table 1. The electrolytes domain was meshed using free triangular elements with increased density of the elements at boundaries where strong concentration or velocity gradients are expected. In particular, a so-called boundary layer was added at the boundary of Fe as shown in Fig. 1b. The time of solving the problem was about 10 min per set of variables using a notebook quipped with Intel Core i7-3517U CPU $2.40 \mathrm{GHz}$, and 4 GB RAM.

The conservation of mass has been verified by calculating the balance of in and out fluxes. The value of OCP is estimated by identifying the value of $V$ (Eq. 7) for which the sum of anodic and cathodic currents at steady-state is null.

Table 1. Values of parameters used for the simulation

\begin{tabular}{|c|c|c|c|}
\hline Parameter & Description & Value & Source \\
\hline$D_{\mathrm{Na}^{+}}$ & Diffusion coefficient of $\mathrm{Na}^{+}$ & $1.3 \cdot 10^{-9} \mathrm{~m}^{2} \mathrm{~s}^{-1}$ & $\operatorname{Ref}[96]$ \\
\hline$D_{H^{+}}$ & Diffusion coefficient of $\mathrm{H}^{+}$ & $9.3 \cdot 10^{-9} \mathrm{~m}^{2} \mathrm{~s}^{-1}$ & $\operatorname{Ref}[96]$ \\
\hline$D_{O H^{-}}^{H^{+}}$ & Diffusion coefficient of $\mathrm{OH}^{-}$ & $5.3 \cdot 10^{-9} \mathrm{~m}^{2} \mathrm{~s}^{-1}$ & $\operatorname{Ref}[96]$ \\
\hline$D_{C l^{-}}$ & Diffusion coefficient of $\mathrm{Cl}^{-}$ & $2.0 \cdot 10^{-9} \mathrm{~m}^{2} \mathrm{~s}^{-1}$ & $\operatorname{Ref}[96]$ \\
\hline$D_{\mathrm{O}_{2}}$ & Diffusion coefficient of $\mathrm{O}_{2}$ & $2.4 \cdot 10^{-9} \mathrm{~m}^{2} \mathrm{~s}^{-1}$ & $\operatorname{Ref}[96]$ \\
\hline$E_{\mathrm{Fe}}^{0}$ & Standard potential & $-0.44 \mathrm{~V}$ & $\operatorname{Ref}[86]$ \\
\hline$E_{\mathrm{O}_{2}}^{0}$ & Standard potential & $0.4 \mathrm{~V}$ & $\operatorname{Ref}[86]$ \\
\hline$k_{\mathrm{O}_{2}}$ & kinetic constant for Eq. 5 & $10^{-5} \mathrm{~ms}^{-1}$ & Adjusted \\
\hline$k_{F e}$ & kinetic constant for Eq. 4 & $1.45 \cdot 10^{-6} \mathrm{~mol} \mathrm{~m}^{-2} \mathrm{~s}^{-1}$ & Adjusted \\
\hline$a_{\mathrm{O}_{2}}$ & cathodic Tafel coefficient & $0.05 \mathrm{~V}$ & Measurement \\
\hline$a_{F e}$ & anodic Tafel coefficient & $0.154 \mathrm{~V}$ & Measurement \\
\hline$c_{b, O_{2}}$ & Initial oxygen concentration & $0.26 \mathrm{~mol} \mathrm{~m}^{-3}$ & Imposed \\
\hline$k_{\mathrm{f}, \mathrm{H}_{2} \mathrm{O}}$ & forward kinetic constant for Eq. 9 & $110^{-8} \mathrm{~mol} \mathrm{~m}^{-3} \mathrm{~s}^{-1}$ & $\operatorname{Ref}[97]$ \\
\hline$k_{\mathrm{b}, \mathrm{H}_{2} \mathrm{O}}$ & backward kinetic constant for Eq. 9 & $1 \mathrm{~mol}^{-1} \mathrm{~m}^{3} \mathrm{~s}^{-1}$ & $\operatorname{Ref}[97]$ \\
\hline
\end{tabular}




\section{Results}

\section{Experimental results}

Visual appearance of the test coupons immediately after testing is shown in Figure 3a. Inthe absence of erodent, red rust is observed only for the higher chloride concentration. Whereas, all the samples eroded with particles were covered with red rust. The experimental polarization curves measured during exposure to the jet are shown in Figure 3(b-d). The general shape of the curves is similar in each case, with low slopes of both anodic and cathodic branches. The density of current is systematically higher when erodent particles are present in the jet. The increment is higher for the increasing content of chloride in the electrolyte. The position of the corrosion potential is systematically shifted towards cathodic values when erodent particles are present in the jet. The values of OCP, corrosion potential and corrosion current determined from the experimental data are summarized in Table 2. 
a)
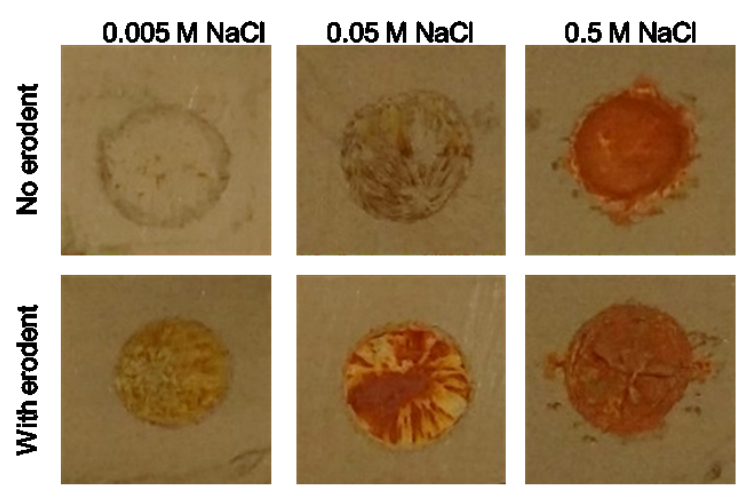

c)

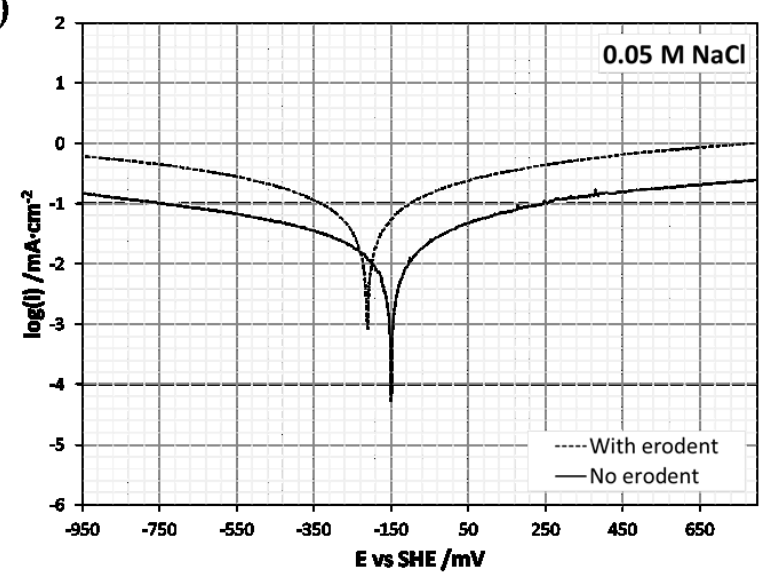

b)

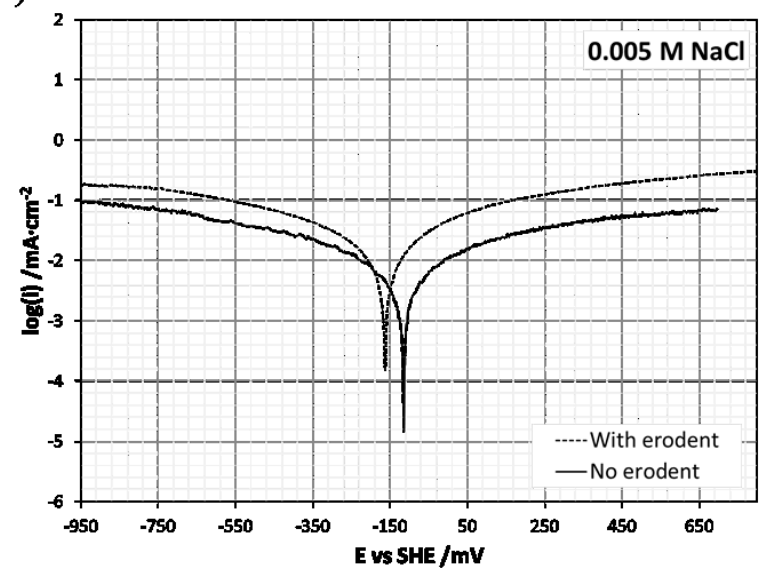

d)

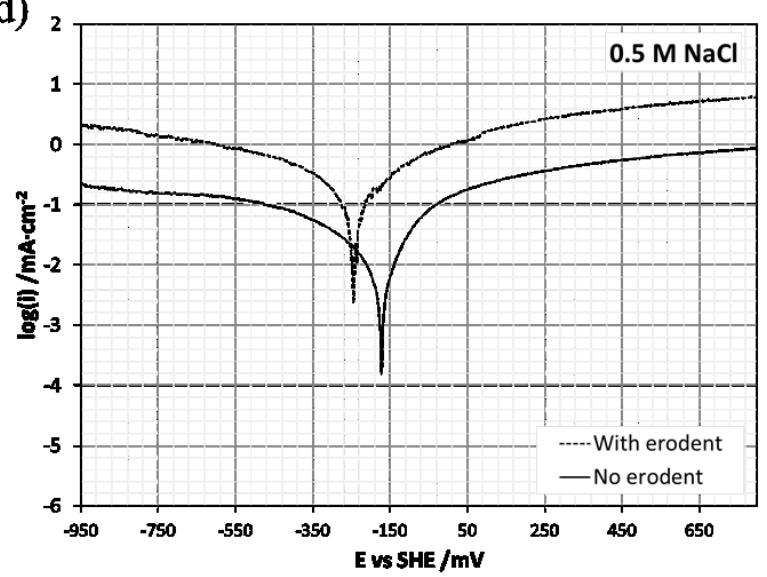

Figure 3. Experimental testing of erosion-enhanced corrosion: a) Visual appearance of the samples immediately after the test.(Need scale markers on the micrographs) The diameter of the eroded/corroded spot is $1 \mathrm{~cm}$; b-d) Polarization curves recorded under impingement of electrolyte with varying concentration of $\mathrm{NaCl}$ in the presence and absence of erodent.

Table 2. Experimental data: The values of OCP measured prior polarization, corrosion potential and corrosion current determined from the polarization curves.

\begin{tabular}{ccccccc}
\hline \multirow{2}{*}{ Parameter } & \multicolumn{2}{c}{$0.005 \mathrm{MNaCl}$} & \multicolumn{2}{c}{$0.05 \mathrm{M} \mathrm{NaCl}$} & \multicolumn{2}{c}{$0.5 \mathrm{M} \mathrm{NaCl}$} \\
\cline { 2 - 6 } & No particles & With particles & No particles & With particles & No particles & With particles \\
\hline E & -174 & -195 & -168 & -215 & -214 & -237 \\
$\mathrm{E}_{\text {corr }}(\mathrm{mV})$ & -115 & -163 & -150 & -181 & -178 & -244 \\
$j_{\text {corr }}\left(\mathrm{mA} / \mathrm{cm}^{2}\right)$ & $10^{-1.67}$ & $10^{-1.17}$ & $10^{-1.20}$ & $10^{-0.62}$ & $10^{-0.69}$ & $10^{0.14}$ \\
\hline
\end{tabular}




\section{Numerical results}

The general distribution of flow velocity and the resulting pressures are shown in Figure 4a. At the surface of the working electrode, the electrochemical reactions and homogeneous reactions result in distribution of the reactants different from non-flow conditions. An example of a steadystate distribution of $\mathrm{pH}$ at the electrode polarized to $0.2 \mathrm{~V}$ vs OCP is shown in Figure $4 \mathrm{~b}$. The distribution of other species is similar to that of $\mathrm{pH}$ even though the potential is applied homogenously on the electrode.

a)

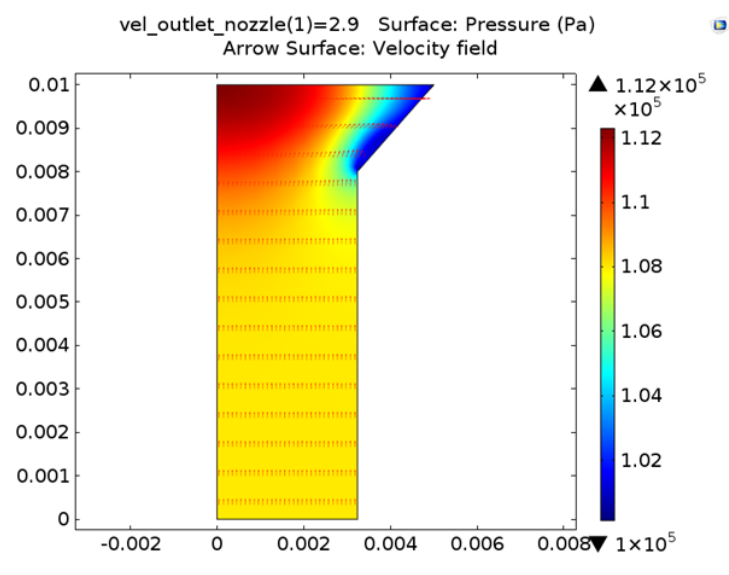

Figure 4. Visualization of selected quantities in the flowing electrolyte determined simulation at steady-state by numerical: a) Velocity field (arrows) and pressure (colo map), b) Distribution of $\mathrm{pH}$ when working electrode is polarized to $0.2 \mathrm{~V}$ vs OCP (anodic polarization).

The polarization curves simulated for the different chloride concentrations and exposure conditions are shown in Figure 5, whereas the corresponding values of $k_{\mathrm{E}-\mathrm{C}}$ are summarized in Table 3. For both cathodic and anodic reactions, the higher content of chloride results in higher values of $k_{\mathrm{E}-\mathrm{C}}$. However, the cathodic and anodic reactions are not sensitive to chloride in the same way. Within the range of chloride concentrations studied here, the cathodic reaction is more accelerated as compared to the anodic one. 


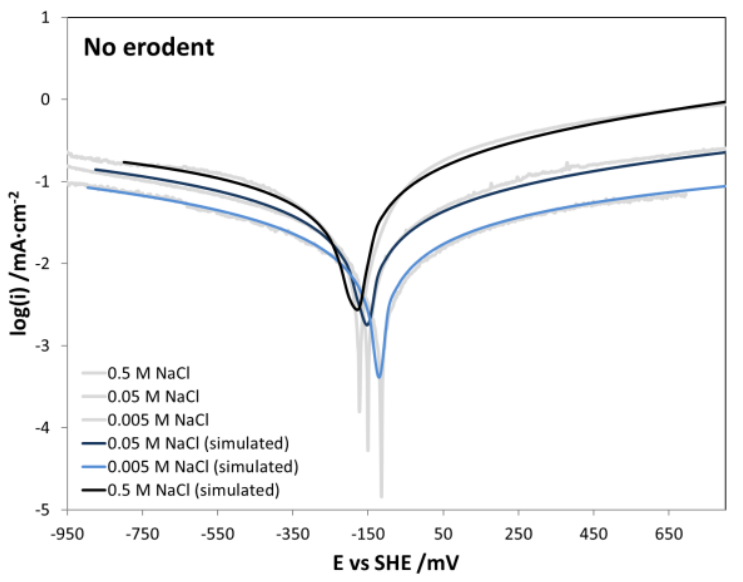

a)

Figure 5. Summary of the simulated polarization curves (color). The experimental data (grey) is the same as that shown in in Figure 3.

Table 3. The values of $k_{\mathrm{E}-\mathrm{C}}$ determined numerically for the anodic and cathodic reactions.

$0.005 \mathrm{M} \mathrm{NaCl}$

$0.05 \mathrm{M} \mathrm{NaCl}$

$0.5 \mathrm{M} \mathrm{NaCl}$

\begin{tabular}{cccc}
\hline Anodic (Eq. 4) & 3.63 & 4.07 & 7.24 \\
Cathodic (Eq. 5) & 2.14 & 4.86 & 9.51 \\
\hline
\end{tabular}

\section{Discussion}

\section{Validity of the experimental data}

The presence of "red rut" on samples following testing is indicative of higher availability of iron ions released during exposure to the jet. This qualitative observation is consistent with the rust layer being continually removed and formed during the erosion-corrosion process. was instantaneously removed. This interpretation is supported by the shape of the polarization curves. Both the anodic and cathodic branches are clearly dominated by mass transport and, in particular, there is no evidence of corrosion products being accumulated at the electrode.

The values of experimental OCP are similar to those measured by Orazem et al. [98], but the values of corrosion potential determined from polarization curves are systematically more anodic than OCP (Table 2). Supposing a steady-state condition under flow, this shift might explained by 
the differential effect that the flow-enhanced mass transfer has over the anodic and cathodic reactions [59]. A prolonged stabilization of OCP under impinging conditions might also play a role [99][52], but the shape of our polarization curves is indicative of steady-state as assessed by the cathodic end of the cathodic branch. A rise of current at this end, such as that reported by Li et al. for carbon steel N80 exposed to saline quartz in slurry pot [100], would indicate that the scan-rate of polarization may be too fast to allow for stabilization, as explained by Fisher et al. [95].

The presence of erodent in the jet results in corrosion potentials shifted towards cathodic values. A similar result was reported by Naz et al. [101] who reported a shift of about $340 \mathrm{mV}$ when particle size increased from 45 to $150 \mu \mathrm{m}$, associating this effect by stability of the externally formed layer of corrosion products. The particles impinging from the jet, also increase the amount of current under both anodic and cathodic polarization, resulting in higher values of corrosion current. Although the value estimated by Tafel extrapolation do not allow for exact quantification because the conditions of applicability are not met [102], the effect is apparent. This result is consistent with the finding that that distribution of corrosion rate correlates with locally increased flow velocity and shear stress measured by an array of electrodes inside a pipe elbow [99]. Also, the rate of diffusion-controlled corrosion can be affected modulation of the thickness of diffusion layer due to damping turbulence near surface as discussed by Amin et al. [103] on the example of pulp fibers.

The effect of chloride concentration is observed on both corrosion potential and corrosion current with no apparent effect on the shape of the polarization curve. Considering that lowcarbon steel is not expected to be passive under our exposure conditions, the addition of chloride is explained by affecting the general mass and charge transfer rather than promoting additional reactions. The effect of chloride is stronger in the presence of erodent particles, which becomes apparent when rearranging the polarization curves (see Figure 5).

\section{Validity of the numerical results}

The simulation can be understood as determining the distribution of all the involved species at all the times and conditions of flow and polarization. The general flow field determined from the 
simulation is similar to that visualized experimentally by particle image velocimentry [104]. However, it should be considered a reasonable approximation rather the correct representation because our model does not feature turbulence, which is likely to be established at the out-flow region. The build-up of turbulence caused by a rapidly turning flow was shown by Nešić to result in greater degree of erosion-corrosion degradation [105].

The general shape and quantity of current are well described by the numerical simulation. In particular, the cathodic and anodic ends do not correspond to the Tafel slope as the amount of current is strongly affected by the flow condition. This results in different from that reported by Guo et al. [52] who found no significant effect of velocity over the polarization curves measured on low-carbo steel and little effect of the presence of sand particles. However, the set-up of Guo et al. was a rotating cylinder electrode particles may slide on the surface rather than impinge it. Our polarization curves are more similar to those reported by Barik et al. [55] for cast nickelaluminum bronze in exposure to $3.5 \% \mathrm{NaCl}$ solution containing $\mathrm{SiO} 2$ erodent. The apparent Tafel slopes derived from the data for carbon steel (S355ML) under flow conditions similar to those reported above and by Choe et al. [104], are also of a very high value (y comparison to ref) and explained by the effect of flow. Since the simulated polarization curves feature both the contributions of both flow and polarization to the total current, the value of Tafel slope associated with activation control is not consistent with the apparent slope resulting in the curve. It should be kept in mind that for determining the value of $k_{\mathrm{E}-\mathrm{C}}$ it is crucial to use the same value of Tafel slope because the method proposed here for quantifying the acceleration of corrosion by erosion relies on the assumption that the additional current observed under particle impingement is caused by faster mass transport rather than change in the mechanism of the electrochemical reactions. It is however not necessarily the case when increasing content of chloride, as formation of intermediate $\mathrm{FeCl}$ may change the kinetcics of the mass transfer process.

Increase of slope in presence of chloride for different microstructures of rebar steel [106]

Although the role of chlorides in initiation of pitting corrosion has long been known [107,108], only recently, the mechanism is shown to be more complex and also affecting carbon steels through induction of localized defects [109], competition of chloride with other reactants [110], and formation of intermediate chloride-containing complexes of iron oxide [111]. However, none of these mechanisms was considered in our model and yet the presence of chloride is well 
captured in reproducing the polarization curves by numerical simulation. Because of the continuous removal of non-adherent corrosion products by the flow, the effect of chloride can be explained principally by the higher electrolyte conductivity allowing for faster charge exchange, generating more current. To a lesser degree, the effect of chloride is represented by slightly different slopes of polarization curves.

\section{Erosion-accelerated corrosion}

The stronger effect that impact of particles has on the anodic and cathodic branches is consistent with the experimental demonstration of $\mathrm{Xu}$ and Tan [112] who showed that impinging particles increase the current of local anodic sites stronger than that of the cathodic ones. A possible mechanism is the localized plastic deformation induced by the particles, changing the properties of the subsubstrate [58], whereas the cathodic reaction is affected only though modulated transport of the reactants and products near the electrode.

It should be kept in mind that in this work we describe the augment of corrosion in terms of electrochemical quantities, which are indicative of mass loss but do not account for the nonFaradaic effects described for an erosive system by Guo et al. [113]. These non-Faradaic effects are mostly associated with generation of debris, a process that does not contribute directly to the corrosion current that is used for determining mass loss, and thus is not a part of erosionenhanced corrosion.

Finally, this study was implemented assuming a laminar flow regime, which is a simplification that does not allow direct incorporation of the particle effect. However, the components exposed to slurry flow is engineering applications are generally subject to turbulent flows, which add a level complexity not considered to date This will be the subject of future work.

\section{Conclusions}

In this work, the erosion-corrosion was tested by means of slurry jet and numerical simulation to quantify the fraction of the E-C synergy attributable to erosion-enhanced corrosion. It was shown that this fraction can be described by means of a proportionality factor of the kinetics coefficient of principal electrochemical reactions. In this sense, both anodic and cathodic reactions are affected by erosion and the anodic reaction is systematically more accelerated by the impinging 
particles. This effect is explained by modification of the steels subsurface. Whereas, the effect of chloride ions is explained by the increased conductivity of the medium and, to a lesser extent, by the interference with the electrochemical reactions without formation of stable corrosion products. However, in order to extend this work for predicting rate of mass loss in real structures, turbulence of the flow and non-Faradaic mass losses must be taken into account.

\section{Acknowledgements}

The authors are very grateful for the support for this project. The sponsorship is from the Chilean National Agency of Research and Development (ANID, FONDECYT Grant No. 1201547).

\section{References}

[1] ASTM International, G40-15 Standard Terminology realting to Wear and Erosion, ASTM Int. G40-15 (2016) 1-9. doi:10.1520/G0040-15.2.

[2] S.S. Rajahram, T.J. Harvey, R.J.K. Wood, Full factorial investigation on the erosion - corrosion resistance of UNS S31603, Tribiology Int. 43 (2010) 2072-2083. doi:10.1016/j.triboint.2010.05.012.

[3] Y. Yang, Y.F. Cheng, Parametric effects on the erosion-corrosion rate and mechanism of carbon steel pipes in oil sands slurry, Wear. 276-277 (2012) 141-148. doi:10.1016/j.wear.2011.12.010.

[4] A.K. Mahmood, A.A. Khadom, Erosion-Corrosion of Low-Carbon Steel in the Absence and Presence of Slurry in Saline Water: Kinetic and Mathematical Views, J. Fail. Anal. Prev. 16 (2016) 1071-1081. doi:10.1007/s11668-016-0180-4.

[5] M.. Mahdavi, S.A.. Shirazi, S.. Karimi, B.S. Mclaury, Parametric study of erosion under high concentrated slurry: Experimental and numerical analyses, in: Proc. ASME-FEDSM 2016, 2016: pp. FEDSM2016-7718.

[6] J. Aguirre, M. Walczak, Multifactorial study of erosion-corrosion wear of a X65 steel by slurry of simulated copper tailing, Tribol. Int. 126 (2018) 177-185. doi:10.1016/j.triboint.2018.04.029.

[7] A. Neville, T. Hodgkiess, H. Xu, An electrochemical and microstructural assessment of erosioncorrosion of cast iron, Wear. 233-235 (1999) 523-534. doi:10.1002/15214176(200201)53:1<5::AID-MACO5>3.0.CO;2-R.

[8] M.A. Islam, T. Alam, Z.N. Farhat, A. Mohamed, A. Alfantazi, Effect of microstructure on the erosion behavior of carbon steel, Wear. 332-333 (2015) 1080-1089. doi:10.1016/j.wear.2014.12.004.

[9] R.J.K. Wood, J.C. Walker, T.J. Harvey, S. Wang, S.S. Rajahram, Influence of microstructure on the erosion and erosion - corrosion characteristics of 316 stainless steel, Wear. 306 (2013) 254- 
262. doi:10.1016/j.wear.2013.08.007.

[10] Y. Zhang, X. Yin, J. Wang, F. Yan, Influence of microstructure evolution on tribocorrosion of 304SS in artificial seawater, Corros. Sci. 88 (2014) 423-433. doi:10.1016/j.corsci.2014.07.062.

[11] W. Zhao, C. Wang, T. Zhang, M. Yang, B. Han, A. Neville, Effects of laser surface melting on erosion-corrosion of X65 steel in liquid-solid jet impingement conditions, Wear. 362-363 (2016) 39-52. doi:10.1016/j.wear.2016.05.006.

[12] J. Malik, I.H. Toor, W.H. Ahmed, Z.M. Gasem, M.A. Habib, R. Ben-Mansour, H.M. Badr, Evaluating the effect of hardness on erosion characteristics of aluminum and steels, J. Mater. Eng. Perform. 23 (2014) 2274-2282. doi:10.1007/s11665-014-1004-x.

[13] Z.B. Zheng, Y.G. Zheng, W.H. Sun, J.Q. Wang, Effect of heat treatment on the structure, cavitation erosion and erosion-corrosion behavior of Fe-based amorphous coatings, Tribol. Int. 90 (2015) 393-403. doi:10.1016/j.triboint.2015.04.039.

[14] J.G.. Chacon Nava, F.H.. Stott, M.M. Stack, The effect of substrate hardness on the erosioncorrosion resistance of materials in low-velocity conditions, Corros. Sci. 35 (1993) 1045-1051.

[15] L.P. McCabe, G. A. Sargent, H. Conrad, Effect of microstructure on the erosion of steel by solid particles, Wear. 105 (1985) 257-277. doi:10.1016/0043-1648(85)90072-9.

[16] G.R. Desale, B.K. Gandhi, S.C. Jain, Effect of erodent properties on erosion wear of ductile type materials, Wear. 261 (2006) 914-921. doi:10.1016/j.wear.2006.01.035.

[17] C.G. Telfer, M.M. Stack, B.D. Jana, Particle concentration and size effects on the erosioncorrosion of pure metals in aqueous slurries, Tribol. Int. 53 (2012) 35-44. doi:10.1016/j.triboint.2012.04.010.

[18] A.R. Dasgupta, B.. Prasad, A.K. Jha, O.P. Modi, D. Das, A.H. Yegneswaran, Effect of sand concentration on slurry erosion of steels, Marerials Trans. JIM. 39 (1998) 1185-1190.

[19] H. Arabnejad, S.A. Shirazi, B.S. McLaury, H.J. Subramani, L.D. Rhyne, The effect of erodent particle hardness on the erosion of stainless steel, Wear. 332-333 (2015) 1098-1103. doi:10.1016/j.wear.2015.01.017.

[20] M.A. Al-Bukhaiti, A. Abouel-Kasem, K.M. Emara, S.M. Ahmed, Particle Shape and Size Effects on Slurry Erosion of AISI 5117 Steels, J. Tribol. 138 (2016) 024503 1-8. doi:10.1115/1.4031987.

[21] T. Frosell, M. Fripp, E. Gutmark, Investigation of slurry concentration effects on solid particle erosion rate for an impinging jet, Wear. 342-343 (2015) 33-43. doi:10.1016/j.wear.2015.08.003.

[22] G.B. Stachowiak, M. Salasi, W.D.A. Rickard, G.W. Stachowiak, The effects of particle angularity on low-stress three-body abrasion-corrosion of 316L stainless steel, Corros. Sci. 111 (2016) 690702. doi:10.1016/j.corsci.2016.06.008.

[23] Z.G. Liu, S. Wan, V.B. Nguyen, Y.W. Zhang, A numerical study on the effect of particle shape on the erosion of ductile materials, Wear. 313 (2014) 135-142. doi:10.1016/j.wear.2014.03.005.

[24] R.S. Lynn, K.K. Wong, H.M. Clark, On the particle size effect in slurry erosion, Wear. 149 (1991) 55-71. doi:10.1016/0043-1648(91)90364-Z.

[25] H.M. Clark, R.B. Hartwich, A re-examination of the "particle size effect" in slurry erosion, Wear. 248 (2001) 147-161. doi:10.1016/S0043-1648(00)00556-1.

[26] M. Lindgren, J. Perolainen, Slurry pot investigation of the influence of erodent characteristics on the erosion resistance of austenitic and duplex stainless steel grades, Wear. 319 (2014) 38-48. doi:10.1016/j.wear.2014.07.006.

[27] M.A. Islam, Z.N. Farhat, Effect of impact angle and velocity on erosion of API X42 pipeline steel under high abrasive feed rate, Wear. 311 (2014) 180-190. doi:10.1016/j.wear.2014.01.005. 
[28] P.C. Okonkwo, R.A. Shakoor, M.M. Zagho, A.M. Amer Mohamed, Erosion behaviour of API X100 pipeline steel at various impact angles and particle speeds, Metals (Basel). 6 (2016). doi:10.3390/met6100232.

[29] H.M. Clark, The influence of the flow field in slurry erosion, Wear. 152 (1992) 223-240. doi:10.1016/j.wear.2003.02.001.

[30] H.M. Clark, K.K. Wong, Impact angle, particle energy and mass loss in erosion by dilute slurries, Wear. 186-187 (1995) 454-464. doi:10.1016/0043-1648(95)07120-2.

[31] H.M. Clark, Particle velocity and size effects in laboratory slurry erosion measurements OR... do you know what your particles are doing?, Tribol. Int. 35 (2002) 617-624. doi:10.1016/S0301679X(02)00052-X.

[32] B. Lu, K. Wang, X. Wan, J. Luo, Effects of slurry $\mathrm{pH}$ on the surface mechanical properties and erosion-corrosion resistance, in: NACE Corros. 2008, n.d.: pp. 1-11.

[33] Z.B. Zheng, Y.G. Zheng, X. Zhou, S.Y. He, W.H. Sun, J.Q. Wang, Determination of the critical flow velocities for erosion-corrosion of passive materials under impingement by $\mathrm{NaCl}$ solution containing sand, Corros. Sci. 88 (2014) 187-196. doi:10.1016/j.corsci.2014.07.043.

[34] B. Yu, D.Y. Li, A. Grondin, Effects of the dissolved oxygen and slurry velocity on erosioncorrosion of carbon steel in aqueous slurries with carbon dioxide and silica sand, Wear. 302 (2013) 1609-1614. doi:10.1016/j.wear.2013.01.044.

[35] O.O. Ige, L.E. Umoru, Effects of shear stress on the erosion-corrosion behaviour of X-65 carbon steel: A combined mass-loss and profilometry study, Tribol. Int. 94 (2016) 155-164. doi:10.1016/j.triboint.2015.07.040.

[36] B.T. Lu, J.L. Luo, Correlation between surface-hardness degradation and erosion resistance of carbon steel - Effects of slurry chemistry, Tribol. Int. 83 (2015) 146-155. doi:10.1016/j.triboint.2014.11.008.

[37] B.R. Tian, Y.F. Cheng, Electrochemical corrosion behavior of X-65 steel in the simulated oil sand slurry. I: Effects of hydrodynamic condition, Corros. Sci. 50 (2008) 773-779. doi:10.1016/j.corsci.2007.11.008.

[38] ASTM International, G119-09 (Reapproved 2016) Standard Guide for Determining Synergism Between Wear and Corrosion, Wear Erosion, Met. Corros. 93 (2009) 1-7. doi:10.1520/G011909.2.

[39] M.M. Stack, B.D. Jana, Modelling particulate erosion-corrosion in aqueous slurries: Some views on the construction of erosion-corrosion maps for a range of pure metals, Wear. 256 (2004) 9861004. doi:10.1016/j.wear.2003.09.004.

[40] B.T. Lu, J.F. Lu, J.L. Luo, Erosion-corrosion of carbon steel in simulated tailing slurries, Corros. Sci. 53 (2011) 1000-1008. doi:10.1016/j.corsci.2010.11.034.

[41] B.T. Lu, J.L. Luo, Synergism of electrochemical and mechanical factors in erosion-corrosion., J. Phys. Chem. B. 110 (2006) 4217-4231. doi:10.1021/jp051985f.

[42] M. Jones, R.J. Llewellyn, Erosion-corrosion assessment of materials for use in the resources industry, Wear. 267 (2009) 2003-2009. doi:10.1016/j.wear.2009.06.025.

[43] S.S. Rajahram, T.J. Harvey, R.J.K. Wood, Erosion-corrosion resistance of engineering materials in various test conditions, Wear. 267 (2009) 244-254. doi:10.1016/j.wear.2009.01.052.

[44] X. Hu, A. Neville, The electrochemical response of stainless steels in liquid-solid impingement, Wear. 258 (2005) 641-648. doi:10.1016/j.wear.2004.09.043.

[45] A. Neville, C. Wang, Erosion - corrosion of engineering steels - Can it be managed by use of 
chemicals ?, 267 (2018) 2018-2026. doi:10.1016/j.wear.2009.06.041.

[46] R. Barker, X. Hu, A. Neville, S. Cushnaghan, Inhibition of flow-induced corrosion and erosioncorrosion for carbon steel pipe work from an offshore oil and gas facility, Corrosion. 69 (2013) 193-203. doi:10.5006/0422.

[47] L. Chaal, C. Deslouis, A. Pailleret, B. Saidani, On the mitigation of erosion-corrosion of copper by a drag-reducing cationic surfactant in turbulent flow conditions using a rotating cage, Electrochim. Acta. 52 (2007) 7786-7795. doi:10.1016/j.electacta.2006.10.013.

[48] R. Malka, S. Nešić, D.A. Gulino, Erosion-corrosion and synergistic effects in disturbed liquidparticle flow, Wear. 262 (2007) 791-799. doi:10.1016/j.wear.2006.08.029.

[49] R. Kuruvila, S.T. Kumaran, M.A. Khan, M. Uthayakumar, A brief review on the erosion-corrosion behavior of engineering materials, Corros. Rev. 36 (2018) 435-447. doi:10.1515/corrrev-20180022 .

[50] S.S. Rajahram, T.J. Harvey, R.J.K. Wood, Evaluation of a semi-empirical model in predicting erosion-corrosion, Wear. 267 (2009) 1883-1893. doi:10.1016/j.wear.2009.03.002.

[51] T.J. Harvey, J.A. Wharton, R.J.K. Wood, Development of synergy model for erosion-corrosion of carbon steel in a slurry pot, Tribology. 1 (2007) 33-47. doi:10.1179/175158407X181471.

[52] H.X. Guo, B.T. Lu, J.L. Luo, Interaction of mechanical and electrochemical factors in erosioncorrosion of carbon steel, Electrochim. Acta. 51 (2005) 315-323. doi:10.1016/j.electacta.2005.04.032.

[53] B.T. Lu, J.L. Luo, F. Mohammadi, K. Wang, X.M. Wan, Correlation between repassivation kinetics and corrosion rate over a passive surface in flowing slurry, Electrochim. Acta. 53 (2008) 7022-7031. doi:10.1016/j.electacta.2008.02.083.

[54] H.X. Guo, B.T. Lu, J.L. Luo, Study on passivation and erosion-enhanced corrosion resistance by Mott-Schottky analysis, Electrochim. Acta. $52 \quad$ (2006) 1108-1116. doi:10.1016/j.electacta.2006.07.026.

[55] R.C. Barik, J.A. Wharton, R.J.K. Wood, K.R. Stokes, Electro-mechanical interactions during erosion-corrosion, Wear. 267 (2009) 1900-1908. doi:10.1016/j.wear.2009.03.011.

[56] V. Hadavi, M. Papini, Numerical modeling of particle embedment during solid particle erosion of ductile materials, Wear. 342-343 (2015) 310-321. doi:10.1016/j.wear.2015.09.008.

[57] J.F. Flores, A. Neville, N. Kapur, A. Gnanavelu, Erosion-corrosion degradation mechanisms of $\mathrm{Fe}-\mathrm{Cr}-\mathrm{C}$ and WC-Fe-Cr-C PTA overlays in concentrated slurries, Wear. 267 (2009) 1811-1820. doi:10.1016/j.wear.2009.02.005.

[58] J. Aguirre, M. Walczak, M. Rohwerder, The mechanism of erosion-corrosion of API X65 steel under turbulent slurry flow: Effect of nominal flow velocity and oxygen content, Wear. 438-439 (2019) 203053. doi:10.1016/j.wear.2019.203053.

[59] A. Pasha, H.M. Ghasemi, J. Neshati, Study of the pitting corrosion of superduplex stainless steel and X-65 carbon steel during erosion-corrosion by cyclic polarisation technique, Corros. Eng. Sci. Technol. 51 (2016) 463-471. doi:10.1080/1478422X.2016.1141546.

[60] A.S. Shehata, S.A. Nosier, G.H. Sedahmed, The role of mass transfer in the flow-induced corrosion of equipments employing decaying swirl flow, Chem. Eng. Process. 41 (2002) 659-666. doi:10.1016/S0255-2701(01)00182-9.

[61] M.H. Abdel-Aziz, Solid-liquid mass transfer in relation to diffusion controlled corrosion at the outer surface of helical coils immersed in agitated vessels, Chem. Eng. Res. Des. 91 (2013) 43-50. doi:10.1016/j.cherd.2012.06.016. 
[62] K. Wang, B.T. Lu, J.L. Luo, Investigation of corrosion enhanced erosion of carbon steel in slurries using nanoindentation, Can. Metall. Q. $50 \quad$ (2011) 181-185. doi:10.1179/000844311X12949291727934.

[63] R. Norling, A. Nylund, The Influence of Temperature on Oxide-Scale Formation during Erosion Corrosion, Oxid. Met. 63 (2005) 87-111. doi:10.1007/s11085-005-1953-4.

[64] M. Antonov, R. Veinthal, E. Huttunen-saarivirta, I. Hussainova, A. Vallikivi, M. Lelis, J. Priss, Effect of oxidation on erosive wear behaviour of boiler steels, Tribiology Int. 68 (2013) 35-44. doi:10.1016/j.triboint.2012.09.011.

[65] J. Tu, L. Sun, J. Xiong, Comparative erosion-corrosion and electrochemical studies of Ni austenitic cast iron in acidic slurry medium, Corros. Eng. Sci. Technol. 50 (2015) 49-55. doi:10.1179/1743278214Y.0000000196.

[66] H. Xu, A. Neville, An electrochemical and microstructural assessment of erosion-corrosion of austenitic cast iron for marine applications, Mater. Corros. 53 (2002) 5-12.

[67] R.J.K. Wood, T.F. Jones, J. Ganeshalingam, N.J. Miles, Comparison of predicted and experimental erosion estimates in slurry ducts, 256 (2004) 937-947. doi:10.1016/j.wear.2003.09.002.

[68] E. Heitz, Chemo-mechanical effects of flow on corrosion, Corrsion. 47 (1991) 135-145. doi:10.5006/1.3585229.

[69] L. Zeng, G.A. Zhang, X.P. Guo, Erosion-corrosion at different locations of X65 carbon steel elbow, Corros. Sci. 85 (2014) 318-330. doi:10.1016/j.corsci.2014.04.045.

[70] E.M. Sherif, A.A. Almajid, K.A. Khalil, H. Junaedi, F.H. Latief, Electrochemical Studies on the Corrosion Behavior of API X65 Pipeline Steel in Chloride Solutions, Int. J. Electrochem. Sci. 8 (2013) 9360-9370.

[71] R. Vera, F. Vinciguerra, M. Bagnara, Comparative study of the behavior of API 5L-X65 grade steel and ASTM A53-B grade steel against corrosion in seawater, Int. J. Electrochem. Sci. 10 (2015) 6187-6198.

[72] A. Gnanavelu, N. Kapur, A. Neville, J.F. Flores, An integrated methodology for predicting material wear rates due to erosion, 267 (2009) 1935-1944. doi:10.1016/j.wear.2009.05.001.

[73] A. Mansouri, H. Arabnejad, S. Karimi, S.A. Shirazi, B.S. Mclaury, Improved CFD modeling and validation of erosion damage due to fine sand particles, Wear. 338-339 (2015) 339-350. doi:10.1016/j.wear.2015.07.011.

[74] M.M. Stack, S.M. Abdelrahman, A CFD model of particle concentration effects on erosioncorrosion of $\mathrm{Fe}$ in aqueous conditions, Wear. 273 (2011) 38-42. doi:10.1016/j.wear.2011.06.024.

[75] D.R. Kaushal, T. Thinglas, Y. Tomita, S. Kuchii, H. Tsukamoto, CFD modeling for pipeline flow of fine particles at high concentration, Int. J. Multiph. Flow. 43 (2012) 85-100. doi:10.1016/j.ijmultiphaseflow.2012.03.005.

[76] S. Lahiri, K.C. Ghanta, Slurry flow modelling by CFD, Chem. Ind. Chem. Eng. Q. 16 (2010) 329343. doi:10.2298/CICEQ091030034L.

[77] C.F. Ihle, A. Tamburrino, S. Montserrat, Computational modeling for efficient long distance ore transport using pipelines, Miner. Eng. 63 (2014) 73-80. doi:10.1016/j.mineng.2014.01.002.

[78] D.R. Kaushal, Y. Tomita, Prediction of Concentration Distribution in Pipeline Flow of Highly Concentrated Slurry, Part. Sci. Technol. 31 (2013) 28-34. doi:10.1080/02726351.2011.639045.

[79] G.V. Messa, G. Ferrarese, S. Malavasi, A mixed Euler-Euler/Euler-Lagrange approach to erosion prediction, Wear. 342-343 (2015) 138-153. doi:10.1016/j.wear.2015.08.015. 
[80] G.V. Messa, S. Malavasi, The effect of sub-models and parameterizations in the simulation of abrasive jet impingement tests, Wear. 370 (2017) 59-72. doi:10.1016/j.wear.2016.10.022.

[81] H.P. Rani, T. Divya, R.R. Sahaya, V. Kain, D.K. Barua, CFD study of flow accelerated corrosion in 3D elbows, Ann. Nucl. Energy. 69 (2014) 344-351. doi:10.1016/j.anucene.2014.01.031.

[82] H.M. El-Batsh, M.A. Doheim, A.F. Hassan, On the application of mixture model for two-phase flow induced corrosion in a complex pipeline configuration, Appl. Math. Model. 36 (2012) 56865699. doi:10.1016/j.apm.2012.01.017.

[83] C. Davis, P. Frawley, Modelling of erosion-corrosion in practical geometries, Corros. Sci. 51 (2009) 769-775. doi:10.1016/j.corsci.2008.12.025.

[84] B. Bozzini, M.E. Ricotti, M. Boniardi, C. Mele, Evaluation of erosion-corrosion in multiphase flow via CFD and experimental analysis, Wear. 255 (2003) 237-245. doi:10.1016/S00431648(03)00181-9.

[85] F. Thébault, B. Vuillemin, R. Oltra, C. Allely, K. Ogle, Modeling bimetallic corrosion under thin electrolyte films, Corros. Sci. 53 (2011) 201-207. doi:10.1016/j.corsci.2010.09.010.

[86] F. Thébault, B. Vuillemin, R. Oltra, C. Allely, K. Ogle, Reliability of numerical models for simulating galvanic corrosion processes, Electrochim. Acta. 82 (2012) 349-355. doi:10.1016/j.electacta.2012.04.068.

[87] A.S. Demeter, O. Dolgikh, A.C. Bastos, D. Deconinck, S. Lamaka, V. Topa, J. Deconinck, Multiion transport and reaction model used to improve the understanding of local current density measurements in presence of concentration gradients around a point current source, Electrochim. Acta. 127 (2014) 45-52. doi:10.1016/j.electacta.2014.02.009.

[88] O. Dolgikh, A.C. Bastos, A. Oliveira, C. Dan, J. Deconinck, Influence of the electrolyte film thickness and $\mathrm{NaCl}$ concentration on the oxygen reduction current on platinum, Corros. Sci. 102 (2016) 338-347. doi:10.1016/j.corsci.2015.10.025.

[89] P. V. Urriola, M. Walczak, M. Rohwerder, Theoretical Efficiency of Metallic Dispersion Coatings for Corrosion Protection at the Cut-Edge, J. Electrochem. Soc. 160 (2013) C305-C315. doi:10.1149/2.019308jes.

[90] J.B. Zu, I.M. Hutchings, G.T. Burstein, Design of a slurry erosion test rig, Wear. 140 (1990) 331344. doi:10.1016/0043-1648(90)90093-P.

[91] M.M. Stack, G.H. Abdulrahman, Mapping erosion-corrosion of carbon steel in oil-water solutions: Effects of velocity and applied potential, Wear. 274-275 (2012) 401-413. doi:10.1016/j.wear.2011.10.008.

[92] K.E. Newman, J and Thomas-Aleya, Electrochemical Systems, in: 3rd ed., Wiley-Interscience, 2004.

[93] E.J.F. Dickinson, J.G. Limon-Petersen, R.G. Compton, The electroneutrality approximation in electrochemistry, J. Solid State Electrochem. 15 (2011) 1335-1345. doi:10.1007/s10008-011$1323-\mathrm{X}$.

[94] F. Thébault, B. Vuillemin, R. Oltra, K. Ogle, C. Allely, Investigation of self-healing mechanism on galvanized steels cut edges by coupling SVET and numerical modeling, Electrochim. Acta. 53 (2008) 5226-5234. doi:10.1016/j.electacta.2008.02.066.

[95] D.A. Fischer, I.T. Vargas, G.E. Pizarro, F. Armijo, M. Walczak, The effect of scan rate on the precision of determining corrosion current by Tafel extrapolation: A numerical study on the example of pure $\mathrm{Cu}$ in chloride containing medium, Electrochim. Acta. 313 (2019) 457-467. doi:10.1016/j.electacta.2019.04.064. 
[96] D.R. Lide, CRC Handbook of Chemistry and Physics, 94th Edition, 2013-2014, 2013. doi:10.1136/oem.53.7.504.

[97] N. Murer, R. Oltra, B. Vuillemin, O. Néel, Numerical modelling of the galvanic coupling in aluminium alloys: A discussion on the application of local probe techniques, Corros. Sci. 52 (2010) 130-139. doi:10.1016/j.corsci.2009.08.051.

[98] M.E. Orazem, J.C. Cardoso, B. Tribollet, U.P.R. Cnrs, Application of a submerged impinging jet for corrosion studies : development of models for the impedance response, Electrochim. Acta. 46 (2001) 3685-3698.

[99] G.A. Zhang, L. Zeng, H.L. Huang, X.P. Guo, A study of flow accelerated corrosion at elbow of carbon steel pipeline by array electrode and computational fluid dynamics simulation, Corros. Sci. 77 (2013) 334-341. doi:10.1016/j.corsci.2013.08.022.

[100] H. Li, Y.H. Liu, Y.Z. Wang, J.M. Ma, B.P. Cai, R.J. Ji, Y.Z. Zhang, Corrosion-erosion wear of N80 carbon steel and 316L stainless steel in saline-quartz slurry, Mater. Corros. 62 (2011) 10511060. doi:10.1002/maco.201106086.

[101] M.Y. Naz, N.I. Ismail, S.A. Sulaiman, S. Shukrullah, Electrochemical and Dry Sand Impact Erosion Studies on Carbon Steel, Sci. Rep. 5 (2015) 16583. doi:10.1038/srep16583.

[102] E. McCafferty, Validation of Corrosion Rates Measured by the Tafel Extrapolation Method, Corros. Sci. 47 (2005) 3202-3215. doi:10.1016/j.corsci.2005.05.046.

[103] N.K. Amin, M.H. Abdel-Aziz, E.S.Z. El-Ashtoukhy, Effect of pulp fiber suspensions on the rate of mass transfer controlled corrosion in pipelines under turbulent flow conditions, Chem. Eng. Res. Des. 92 (2014) 2333-2338. doi:10.1016/j.cherd.2014.01.023.

[104] S.B. Choe, S.J. Lee, Effect of flow rate on electrochemical characteristics of marine material under seawater environment, Ocean Eng. 141 (2017) 18-24. doi:10.1016/j.oceaneng.2017.05.035.

[105] S. Nešić, Using computational fluid dynamics in combating erosion-corrosion, Chem. Eng. Sci. 61 (2006) 4086-4097. doi:10.1016/j.ces.2006.01.052.

[106] P.K. Katiyar, P.K. Behera, S. Misra, K. Mondal, Comparative Corrosion Behavior of Five Different Microstructures of Rebar Steels in Simulated Concrete Pore Solution with and Without Chloride Addition, J. Mater. Eng. Perform. 28 (2019) 6275-6286. doi:10.1007/s11665-019-04339$\mathrm{x}$.

[107] G.S. Frankel, Pitting Corrosion of Metals. A Review of the Critical Factors, J. Electrochem. Soc. 145 (1998) 2186-2198. doi:10.1149/1.1838615.

[108] G.S. Frankel, ERRATA to "Pitting Corrosion of metals. A Review of the Critical Factors," J. Electrochem. Soc. 145 (1998) 1998.

[109] N.A. Gladkikh, M.A. Maleeva, L.B. Maksaeva, M.A. Petrunin, A Study of the Initial Stages of Local Dissolution of Carbon Steel in Chloride Solution, Prot. Met. Phys. Chem. Surfaces. 54 (2018) 1260-1265. doi:10.1134/S2070205118070109.

[110] M.H. Wood, T.J. Wood, R.J.L. Welbourn, J. Poon, D.C. Madden, S.M. Clarke, An X-ray and Neutron Reflectometry Study of Iron Corrosion in Seawater, Langmuir. 34 (2018) 5990-6002. doi:10.1021/acs.langmuir.8b00378.

[111] N. V. Likhanova, N. Nava, O. Olivares-Xometl, M.A. Domínguez-Aguilar, P. Arellanes-Lozada, I. V. Lijanova, J. Arriola-Morales, L. Lartundo-Rojas, Corrosion evaluation of pipeline steel API 5L X52 in partially deaerated produced water with high chloride content, Int. J. Electrochem. Sci. 13 (2018) 7949-7967. doi:10.20964/2018.08.13.

[112] Y. Xu, M.Y. Tan, Probing the initiation and propagation processes of flow accelerated corrosion 
and erosion corrosion under simulated turbulent flow conditions, Corros. Sci. 151 (2019) 163-174. doi:10.1016/j.corsci.2019.01.028.

[113] H.X. Guo, B.T. Lu, J.L. Luo, Non-Faraday material loss in flowing corrosive solution, Electrochim. Acta. 51 (2006) 5341-5348. doi:10.1016/j.electacta.2006.02.018. 